\title{
Novel Vermilion / Greenish Blue Electrochromism of PPTA / Iridium Oxide / Au Thin Films Prepared by Electrodeposition
}

\author{
Jun YANO, ${ }^{*}$ Kenji NOGUCHI, ${ }^{\text {a }}$ Sumio YAMASAKI, ${ }^{\mathrm{a}}$ and Suzuko YAMAZAKI ${ }^{\mathrm{b}}$
}

\author{
Department of Engineering Science, Niihama National College of Technology (Yagumocho 7-1, Niihama, Ehime 792- \\ 8580, Japan) \\ aFaculty of Engineering, Kyushuı Sangyo University (Matsukadai 2-3-1, Higasi ku, Fukuoka, Fukuoka 813-8503, Japañ) \\ ${ }^{b}$ Faculty of Science, Yamaguchi University (Yoshida 1677-1, Yamaguchi, Yamaguchi 753-8512, Japan)
}

Received October 22, 2003 ; Accepted February 13, 2004

\begin{abstract}
An aramid resin, poly( $p$-phenylene terephtalamide) (PPTA) was available on an ITO electrode as a stable matrix film. Electrochromic iridium oxide was electrodeposited on the electrode. In the oxidized state, original iridium oxide without PPTA film showed blue, while the PPTA / iridium oxide film showed greenish blue: the maximum absorption wavelength of the original iridium oxide film was about $650 \mathrm{~nm}$, while that of the PPTA / iridium oxide film was about $600 \mathrm{~nm}$. The XPS-biding energy of $\mathrm{Ir} 4 \mathrm{f}_{5 / 2}$ and $\mathrm{Ir} 4 \mathrm{f}_{7 / 2}$ electrons was shifted to about $2 \mathrm{eV}$ higher energy, meaning that the color change was probably due to donating of the lone pair electrons of PPTA to the indium. The electrodeposition of Au on the PPTA / iridium oxide film was carried out. The obtained Au-electrodeposited PPTA / iridium oxide film showed quite different electrochromic properties. New redox current peaks appeared in the CV of the film. The film was colored vermilion in the reduced state and greenish blue in the oxidized state. The XPS-biding energy of Ir $4 f_{5 / 2}$ and Ir $4 f_{7 / 2}$ electrons was shifted to about $2 \mathrm{eV}$ lower energy, implying that the electrodeposition of $\mathrm{Au}$ transformed the electronic state and structure of iridium oxide, suggesting the formation of a - $\mathrm{Au}-\mathrm{Cl}-\mathrm{Ir}$ - binuclear $\mathrm{Cl}$ bridged complex and/or the plasmon absorption of the Au microparticles dispersed in the PPTA film.
\end{abstract}

Key Words : Electrochromism, Iridium Oxide, Poly( $p$-phenylene terephtalamide), Electrodeposition of Au, Vermilion Color

\section{Introduction}

Some metal oxides show electrochromism. ${ }^{1)}$ Among the metal oxides, iridium oxide is widely recognized as an excellent electrochromic display (ECD) material about which many studies have been reported. According to Gottesfeld's papers, ${ }^{2,3)}$ advantages of this material over other electrochromic inorganic oxides such as $\mathrm{WO}_{3}$ are shown to include: (1) fast response; (2) strong absorbance by the colored state throughout the visible spectral region; (3) good open-circuit memory; and (4) an operating potential range which avoids electrolyte decomposition. Iridium oxide becomes blue in the oxidized state and colorless in the reduced state. If new colors were added to the color change, the ECD applicability of iridium oxide could be expanded. However, such attempts are very limited in spite of several reports dealing with electrochromic iridium oxide. ${ }^{1-24)}$

Several preparation methods have been reported for iridium oxide film. Among the methods, electrodeposition methods give iridium oxide films with excellent ECD properties. ${ }^{4}{ }^{5)}$ The redox reaction is determined by the XPS-biding energies of Ir-O bond and Ir-OH bond: ${ }^{2}$ )

$$
\begin{aligned}
& \operatorname{Ir}(\mathrm{OH})_{\mathrm{n}}(\text { colorless }) \underset{ }{ } \\
& \quad \operatorname{IrO}_{\mathrm{x}}(\mathrm{OH})_{\mathrm{n}-\mathrm{x}}(\text { blue })+\mathrm{xH}^{+}+\mathrm{xe}^{-}
\end{aligned}
$$

Although the electrodeposited iridium oxide film exhibits excellent ECD properties, the film contains a large amount of water, and is so soft that it is easily scratched. The water can be removed from the film with heat treatment, and the film becomes hard and resistant to scratching. ${ }^{6)}$ Unfortunately, however, the heat treatment affects the ECD properties: the reversibility of the coloring-decoloring reaction and the lifetime of color changes are much lower that those of the original film.

The scratching problem would be solved if iridium oxide was electrodeposited in a stable matrix polymer film. A free-standing ECD film could be obtained and a different color change could be achieved because of the different electronic surroundings. In addition, a new color other than that displayed by the original iridium oxide could appear with metal electrodeposition. In this study, we used an aramid resin, poly( $p$-phenylene terephtalamide) (PPTA), as the matrix polymer film, which is stable and permeable to dissolved species. ${ }^{25)}$ To obtain a new color, we further electrodeposited Au on the PPTA / iridium oxide film. The ingress of $\mathrm{Au}$ into $\mathrm{WO}_{3}$ film transforms the electronic state of $\mathrm{WO}_{3}$, and the $\mathrm{Au}-\mathrm{WO}_{3}$ film shows a new color change other than the original $\mathrm{WO}_{3}$ film. ${ }^{26)}$ Likewise, the Au-electrodeposited PPTA / iridium oxide film showed new color electrochromism: greenish blue in the oxidized state $(+0.8 \mathrm{~V})$ and vermilion in the reduced state $(-0.2 \mathrm{~V})$.

\section{Experimental}

All chemicals were of reagent grade and used without 
further purification. A PPTA film with $12 \mu \mathrm{m}$ thickness was prepared on the ITO electrode substrate by previously described method. ${ }^{27}$ ) The electrodeposition of iridium oxide was carried out based on Yamanaka's methods. $^{6,7)}$ The employed electrodepositing solution was $0.052 \mathrm{~mol} \mathrm{dm}^{-3} \mathrm{IrCl}_{4}$ aqueous solution containing $30 \mathrm{wt}$ $\% \mathrm{H}_{2} \mathrm{O}_{2}$ and $0.04 \mathrm{~mol} \mathrm{dm}^{-3}(\mathrm{COOH})_{2}$ and aged in the dark for two days for stabilization. The iridium oxide was electrodeposited by constant-potential electrolysis at + $0.7 \mathrm{~V}$ until the charge passed was $0.3 \mathrm{C} \mathrm{cm}^{-2}$. The thickness of the iridium oxide was about $2 \mu \mathrm{m}$. The electrodepositing solution of $\mathrm{Au}$ was a $0.1 \mathrm{M} \mathrm{HAuCl}_{4}$ aqueous solution, and the $\mathrm{Au}$ was electrodeposited by constantpotential electrolysis at $-0.2 \mathrm{~V}$. In addition, aqueous solutions were prepared using double-distilled water.

A standard three-electrode system was employed for every electrolysis and electrochemical measurement. The working electrode on which the PPTA film was precoated was an ITO coated glass plate $0.8 \mathrm{~cm}$ wide and 5 $\mathrm{cm}$ long. The ITO plate was cut from a large ITO glass plate with 1-mm thickness supplied by the Nippon Sheet Glass Co. The surface electric resistance was $30 \Omega \square$. Prior to use, the ITO plate electrode was washed with acetone and then with water. $\mathrm{A}$ commercial $\mathrm{Ag} / \mathrm{AgCl}$ electrode was used as the reference electrode and a $\mathrm{Pt}$ plate electrode as the counter electrode. The three electrodes were arranged in the optical quartz cell only when the absorption spectra were measured. The arrangement of the electrodes in the cell chamber was the same as previously described (Fig. 1).

Electrolyses were conducted using a Hokuto Denko HA-501 potentiostat/galvanostat connected with a Hokuto Denko HB-104 function generator and with a Hokuto Denko HF-201 coulometer. Cyclic voltammograms (CVs) were recorded on a Graphtec WX-2400 $x-y$ recorder. The absorption spectra of the films were obtained using a

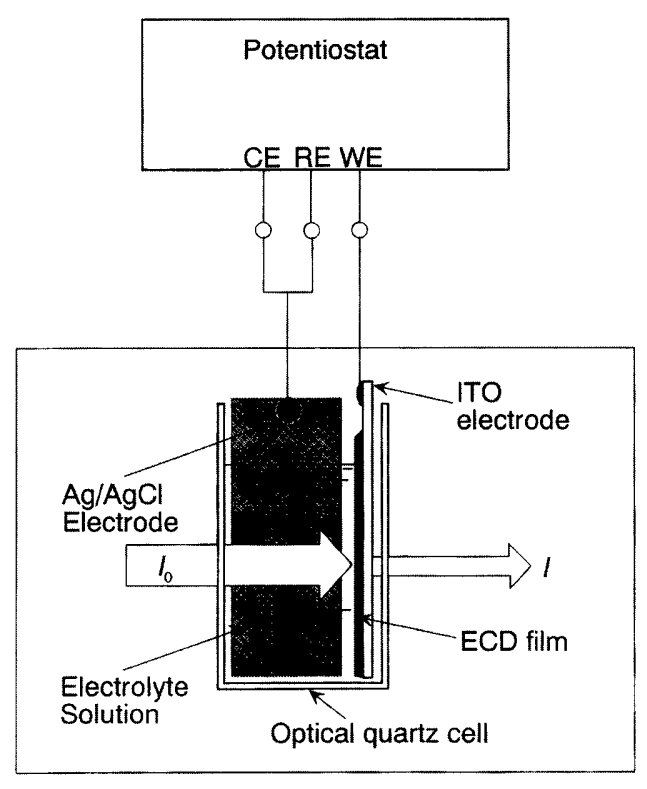

Chamber of spectrophotometer

Fig. 1 Schematic drawing of the arrangement of the working electrode (ITO electrode) and the $\mathrm{Ag} / \mathrm{AgCl}$ electrode in the spectrophotometer cell chamber.
JASCO V-530 spectrophotometer.

To examine the oxidation level of iridium, the XPS spectra of the films were measured. The XPS spectra were obtained from a Perkin-Elmer ESCA PHI 5400 spectrometer using a $\mathrm{Mg} K \alpha$ anode at a power of about 400 $\mathrm{W}$. The vacuum level during the measurement was less than $10^{-9}$ torr. The $\mathrm{C}(1 \mathrm{~s})$ binding energy of $284.6 \mathrm{eV}$ was used as the internal standard.

The switching time and lifetime of the color change of the films were estimated from plots of both the current and absorbance response to the applied square-wave potentials. The potentials were controlled with the potentiostat system previously described except for the recorder. The transient current response was recorded using a Rikadenki R-61 K x-t recorder with wave memory functions. The transient absorbance response at the maximum absorption wavelength was detected by amplifying the direct voltage signals from the photomultiplier of the spectrophotometer. The signals were also recorded using the same $x$-t recorder.

The morphologies of the obtained films were observed with a Hitachi S-2300 scanning electron microscope (SEM) and the film thickness was determined from the SEM observations. The X-ray diffraction (XRD) patterns were obtained using a Rigaku RINT $2400 \mathrm{~V}$ with $\mathrm{Cu} K \alpha$ radiation.

\section{Results and Discussion}

\section{1 Electrochromism of the PPTA / iridium oxide film}

To examine how the PPTA matrix film influences the electrochromism of iridium oxide, the CVs and absorption spectra were measured. Iridium oxide was electrodeposited on an ITO electrode and the PPTA-precoated ITO electrode until the charge passed was $0.3 \mathrm{C} \mathrm{cm}^{-2}$. The PPTA film comprizes many porous layers, and it is permeable to dissolved species. ${ }^{25)}$ Dissolved ions and molecules pass freely through the film and reach the electrode substrate. Iridium oxide can be electrodeposited on the PPTA-precoated ITO electrode even though the whole electrode surface is covered by the PPTA film. Figure 2 shows the CVs of the iridium oxide film and the PPTA / iridium oxide film in $0.1 \mathrm{~mol} \mathrm{dm}^{-3} \mathrm{HClO}_{4}$ aqueous solution. The reversible redox current peaks due to the coloring-decoloring reaction (eqn. (1)) are evident at about $0.6 \mathrm{~V}$. For the redox current peaks, the anodic peak potentials are the same, while the cathodic peak potentials of the PPTA / iridium oxide film is $35 \mathrm{mV}$ higher than that of the iridium oxide film. All the current peaks were directly proportional to the scan rate, not to the root of the scan rate, implying that the reactions were controlled by the charge transfer process of iridium oxide on the electrode.

In spite of almost the same $\mathrm{CV}$ behavior, the color in the oxidized state differed slightly from each other. In the oxidized state, the original iridium oxide film became dark blue, while the PPTA-iridium oxide film was greenish blue. The absorption spectra are shown in Fig. 3. The maximum absorption wavelength is about $650 \mathrm{~nm}$ for the iridium oxide film and about $600 \mathrm{~nm}$ for the PPTA- 


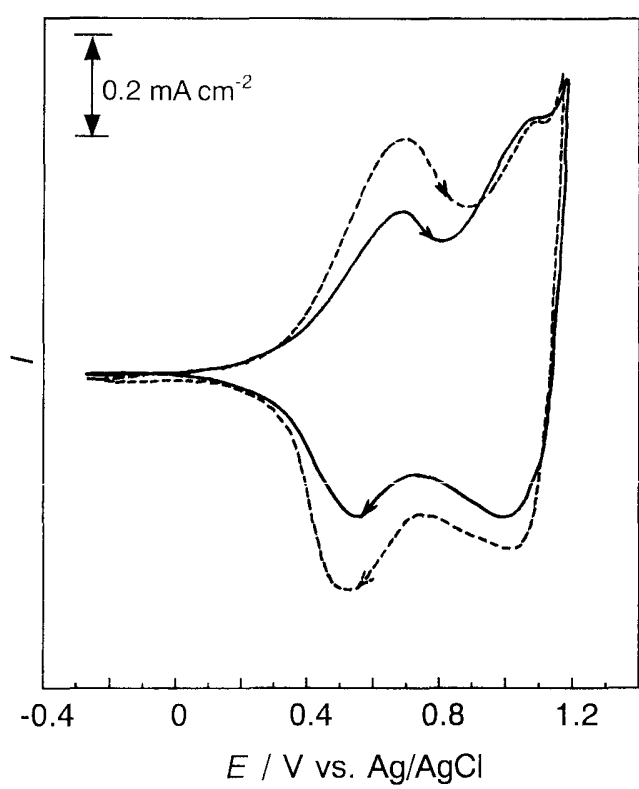

Fig. $2 \mathrm{CVs}$ at $10 \mathrm{mV} \mathrm{s}^{-1}$ of the iridium oxide film (------) and the PPTA / iridium oxide film (- - in $0.1 \mathrm{~mol}$ $\mathrm{dm}^{-3} \mathrm{HClO}_{4}$ aqueous solution.

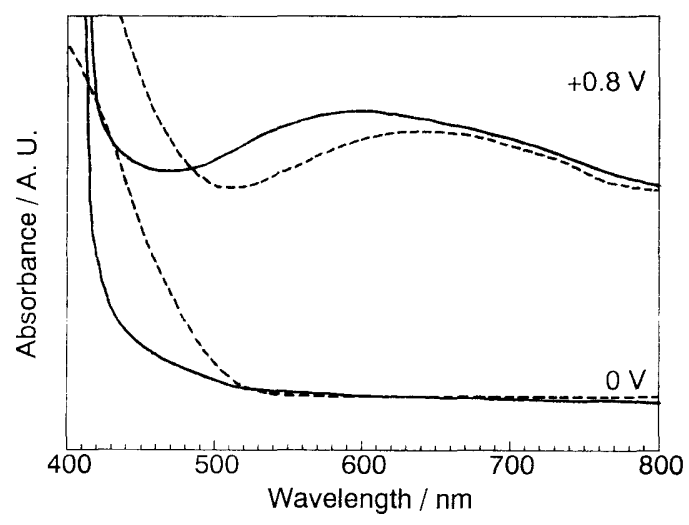

Fig. 3 Visible and near-infrared absorption spectra of the iridium oxide film (--..---) and the PPTA / iridium oxide film (-) at +0.8 and $0 \mathrm{~V}$ in $0.1 \mathrm{~mol} \mathrm{dm}^{-3} \mathrm{HClO}_{4}$ aqueous solution.

iridium oxide film. The difference in the color is probably due to the oxidation level of the iridium. Figure 4 illustrates the XPS spectra of $\operatorname{Ir} 4 \mathrm{f}_{5 / 2}$ and $\operatorname{Ir} 4 \mathrm{f}_{7 / 2}$ electrons of the films. The XPS-biding energies of $\mathrm{Ir} 4 \mathrm{f}_{5 / 2}$ and Ir $4 \mathrm{f}_{7 / 2}$ electrons of the iridium oxide film are in fair agreement with those reported previously, ${ }^{9-11)}$ indicating that the average valence of the iridium in the colored iridium oxide film is very near 4.0. The XPS-biding energies of the PPTA / iridium oxide film is about $2 \mathrm{eV}$ higher than that of the iridium oxide film, suggesting a higher oxidation level of the iridium in the PPTA / iridium oxide film. A probable speculation for the cause is the donating of the lone pair electrons of PPTA to the iridium. There are many lone pair electrons on the oxygen and nitrogen atoms in the PPTA polymeric backbone (Fig. 5), which are available for donating. The donating may enhance the oxidation level of the iridium in the PPTA / iridium oxide film.

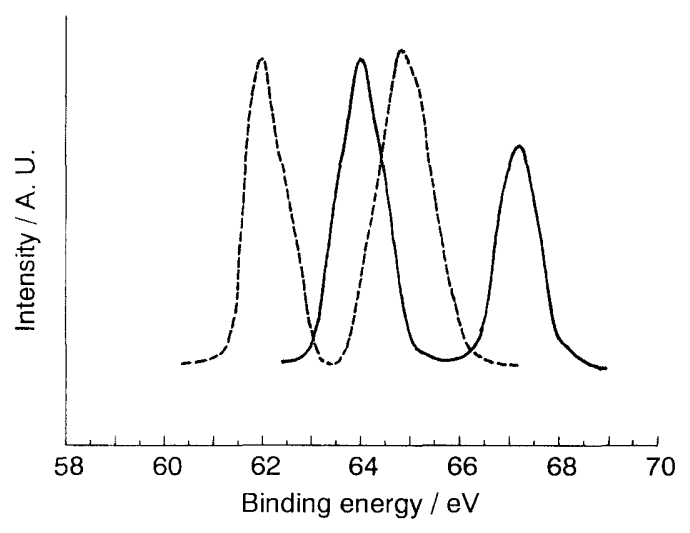

Fig. 4 XPS spectra of $\operatorname{Ir} 4 \mathrm{f}_{5 / 2}$ and Ir $4 \mathrm{f}_{7: 2}$ electrons of the iridium oxide film (---.-.) and the PPTA / iridium oxide film $(-)$.

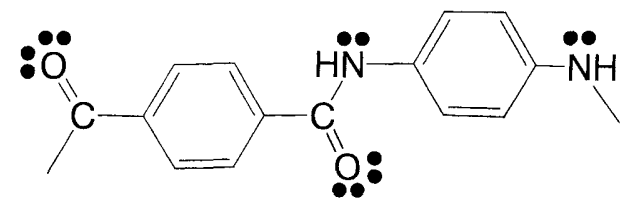

Fig. 5 Unit molecular structure of PPTA.

\section{2 Electrochromism of Au-electrodeposited PPTA $/$ iridium oxide film}

In order to obtain a different color other than that of the original inorganic ECD films, other metal oxides and noble metals have been introduced into the original films. For $\mathrm{WO}_{3}$ film which shows blue-colorless electrochromism, red color tones were obtained for $\mathrm{Au}-\mathrm{WO}_{3}$ film, although the mechanisms are not yet wellunderstood. ${ }^{7}$ In this study, Au was electrodeposited on the original iridium oxide film and on the PPTA / iridium oxide film. Unfortunately, however, the Au / iridium oxide film had almost the same electrochromism as the original iridium oxide film, regardless of the electrodeposited amount of Au. On the other hand, the PPTA / iridium oxide / Au film showed quite different electrochromism from that of the original iridium oxide. The film became greenish blue in the oxidized state and vermilion in the reduced state. This color change was first obtained for the iridium oxide system. Figure 6 shows the absorption spectra of the reduced and oxidized film. The absorption spectra of the PPTA / iridium oxide film are also shown for comparison. It is interesting to find the new absorption peak at around $550 \mathrm{~nm}$ with a relatively large absorption intensity from 400 to $500 \mathrm{~nm}$. It is noteworthy that the absorption peak hardly vanishes in the reduced state at $-0.2 \mathrm{~V}$. That makes the film vermilion in the reduced state.

Different behavior was observed for the $\mathrm{CV}$ data and the XPS-biding energies of $\operatorname{Ir} 4 \mathrm{f}_{5,2}$ and $\operatorname{Ir} 4 \mathrm{f}_{7 / 2}$ electrons of the PPTA / iridium oxide / $\mathrm{Au}$ film, compared with those of the PPTA / iridium oxide film. Figure $7 \mathrm{com}$ pares the CVs of the PPTA / iridium oxide / Au film and the PPTA / iridium oxide film. Besides the redox current peaks originating from the reaction of eqn. (1), a new redox current is evident at around $0 \mathrm{~V}$ in the $\mathrm{CV}$ of the 


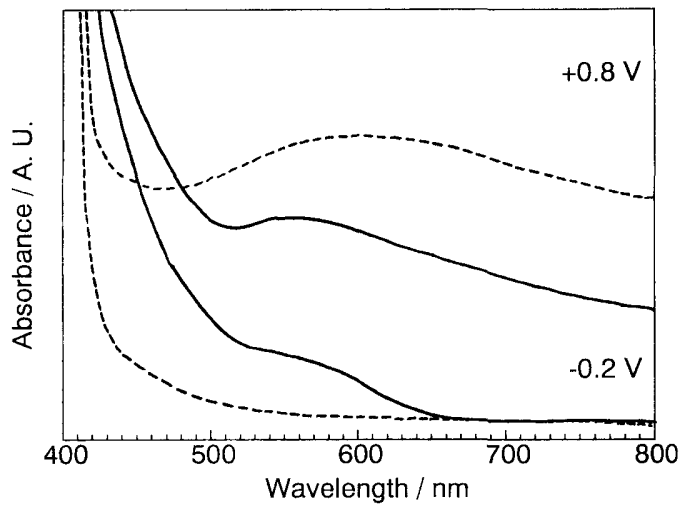

Fig. 6 Visible and near-infrared absorption spectra of the PPTA / iridium oxide film (--------) and the PPTA / iridium oxide / $\mathrm{Au}$ film (-) at +0.8 and $-0.2 \mathrm{~V}$ in 0.1 mol dm ${ }^{-3} \mathrm{HClO}_{4}$ aqueous solution.

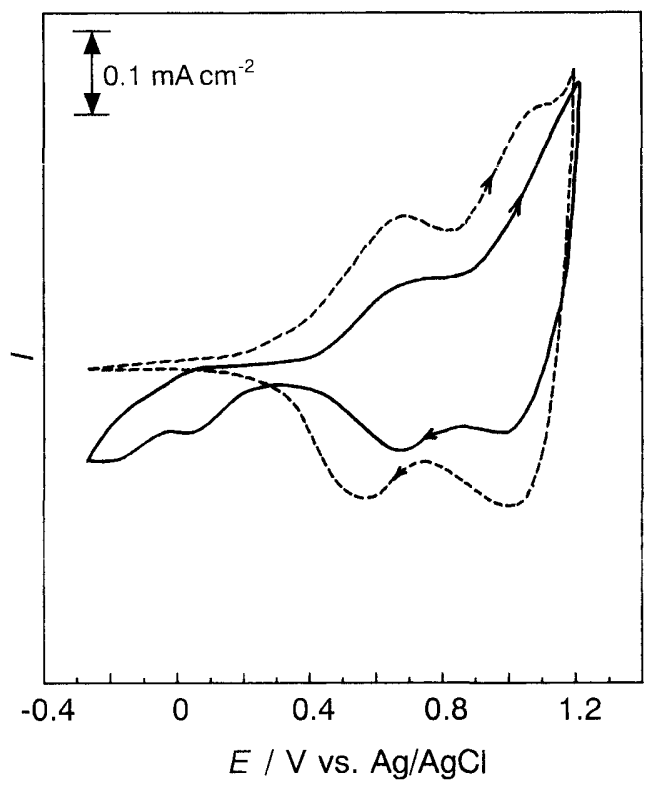

Fig. $7 \mathrm{CVs}$ at $10 \mathrm{mV} \mathrm{s}^{-1}$ of the PPTA / iridium oxide film (--.--) and the PPTA / iridium oxide / $\mathrm{Au}$ film (in $0.1 \mathrm{~mol} \mathrm{dm} \mathrm{dm}^{-3} \mathrm{HClO}_{4}$ aqueous solution.

PPTA / iridium oxide / Au film. There is no doubt that the new color, vermilion, is related to the new redox current. The XPS-biding energies of $\operatorname{Ir} 4 \mathrm{f}_{5 / 2}$ and $\operatorname{Ir} 4 \mathrm{f}_{7 / 2}$ electrons of the PPTA / iridium oxide / Au film were about $2 \mathrm{eV}$ lower than those of the PPTA / iridium oxide film (Fig. 8). This shift is probably due to the disappearance of the donating of PPTA by the Au electrodeposition. The donating of the lone pair electrons of PPTA to the iridium disappears, and the XPS spectral pattern is almost the same as that of the iridium oxide without the PPTA film (see the dashed line in Fig. 3).

The obtained results can be explained mainly by -Au-Cl-Ir- binuclear Cl-bridged complex formation. The electrodeposition of Au occurs through the electroreduction of $\mathrm{AuCl}_{4}{ }^{-}$. When the electroreduction takes place on the PPTA / iridium oxide film, the binuclear Cl-bridged complex is probably formed, at least in part. Once the binuclear Cl-bridged complex is formed, it scarcely decomposes during electrooxidation, as can be seen in the

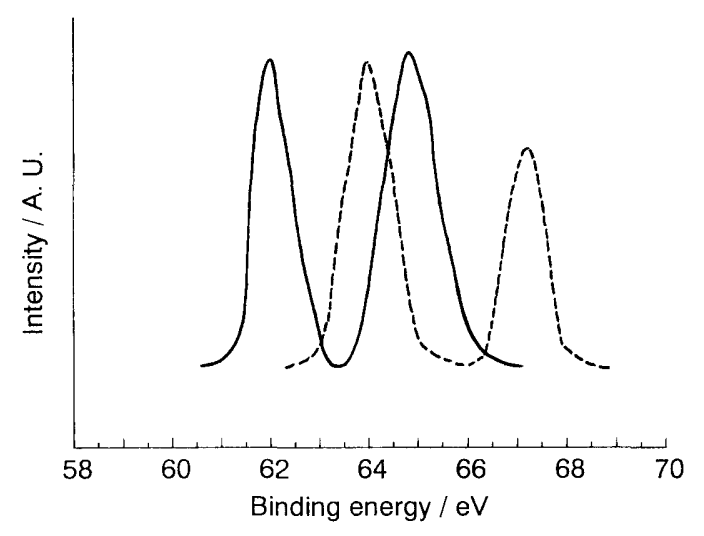

Fig. 8 XPS spectra of Ir $4 \mathrm{f}_{5 / 2}$ and Ir $4 \mathrm{f}_{7 / 2}$ electrons of the PPTA / iridium oxide film (---------) and the PPTA / iridium oxide / Au film (-

$\mathrm{CV}$ and absorption spectral data. In Fig. 7, the irreversible redox peak current at around $0 \mathrm{~V}$ is probably due to the redox reaction of the binuclear $\mathrm{Cl}$-bridged complex partially formed in the PPTA / iridium oxide film. The current is much smaller than the redox current of the coloring-decoloring reaction (eqn. (1)), and little color change of the binuclear Cl-bridged complex occurs. Therefore, the color change of the film originates in the overlap of the coloring-decoloring reaction (eqn. (1)) and the vermilion color of the complex.

The binuclear Cl-bridged complex could not be formed if there was no $\mathrm{Cl}$ source. To make sure this, two $\mathrm{Au}$ deposited PPTA / iridium oxide films were prepared: (A) PPTA / iridium oxide film covered with vapor-deposited gold film and (B) PPTA / iridium oxide film electrodeposited by gold using a different electrodepositing solution, which was a $\mathrm{Na}_{3} \mathrm{PO}_{4}\left(15 \mathrm{~g} \mathrm{dm} \mathrm{dm}^{-3}\right) / \mathrm{Na}_{2} \mathrm{HPO}_{4}(20 \mathrm{~g}$ $\mathrm{dm}^{-3}$ ) buffer solution containing $0.014 \mathrm{~mol} \mathrm{dm}^{-3} \mathrm{KAu}$ $(\mathrm{CN})_{2}$. mol $\mathrm{dm}^{-3}$. Both the voltammetric behavior and absorption spectra at different potentials were almost the same as those of the PPTA / iridium oxide film (Figs. 2 and 3). For the films (A) and (B), the deposited gold barely influenced the electrochromic properties of the PPTA / iridium oxide film. This fact strongly supports that the new color change is due to the formation of the binuclear Cl-bridged complex.

There is still another reason why the PPTA / iridium oxide / Au film shows the vermilion color. The film contains not only the binuclear Cl-bridged complex but also the microparticles of metallic gold. The absorption band from 520 to $660 \mathrm{~nm}$ in the reduced PPTA / iridium oxide / Au film may be assigned to the plasmon absorption of the microparticles of metallic gold dispersed in the film.

3. 3 Morphology of the PPTA-iridium oxide film

We have already shown several properties of the PPTA film: ${ }^{6,8,12)}$ (i) it is obtainable on the electrode substrate as a stable film by electrodeposition; (ii) dissolved species are pearmeable through the PPTA film because of its porosity; (iii) the PPTA film-coated electrode is so electroactive that electrolysis can be carried out using the electrode; (iv) the PPTA film has a layer-stacking structure. The SEM observations were performed with- 
out covering with vapor-deposited gold film. No SEM image of the PPTA film without iridium oxide was obtained because PPTA is an electronic insulator. On the other hand, the electronic conductivity of iridium oxide made a sharp SEM image. The SEM image of the PPTA / iridium oxide film is shown in Fig. 9(a). The fact that the layer-stacking structure of the PPTA film is evident implies that iridium oxide is electrodeposited inside the whole PPTA film. The SEM image of the PPTA / iridium oxide / Au film shows that the metal gloss of gold covers over the film (Fig. 9(b)).

3. 4 Switching time and lifetime in the electrochromism

To examine the switching time and lifetime of the iridium oxide, PPTA / iridium oxide and PPTA / iridium oxide / Au films, the absorbance responses of the films on the ITO electrode were measured versus the squarewave potential pulse at the initial stage. The absorbance was monitored at $650 \mathrm{~nm}$ for the iridium oxide film, at $600 \mathrm{~nm}$ for the PPTA / iridium oxide film and at $550 \mathrm{~nm}$ for the PPTA / iridium oxide / Au film. The absorbance responses are indicated in Fig. 10. The switching time of the PPTA / iridium oxide film is almost the same as that of the iridium oxide film and is found to be about $10 \mathrm{~s}$. It is interesting to find that the PPTA / iridium oxide / $\mathrm{Au}$ film has the shortest switching time of about $5 \mathrm{~s}$.

As can readily be seen in Fig. 9(b), gold covers over

\section{(a) PPTA-iridium oxide film}

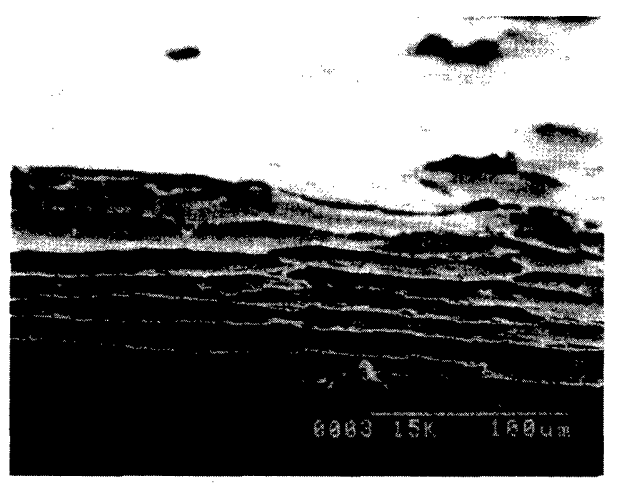

(b) Au-electrodeposited PPTA-iridium oxide film

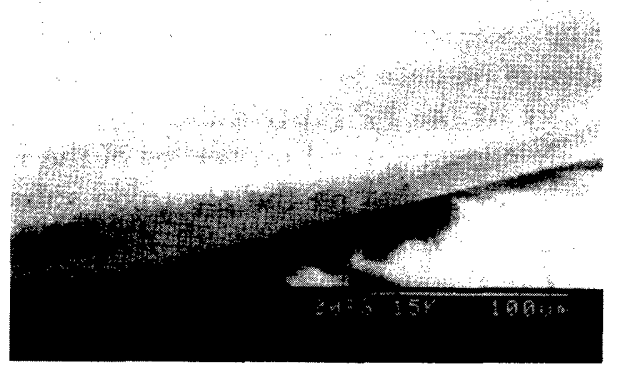

Fig. 9 SEM photographs of the PPTA / iridium oxide film (a) and the PPTA / iridium oxide / Au film (b). the film surface. This means that gold is electrodeposited inside the film as well because the PPTA film is an electronic insulator. Probably the gold inside the film promotes the electronic connection between the iridium oxide and the electrode substrate. This reflected the CV behavior of the PPTA / iridium oxide / Au films with the same amount of iridium oxide and different amount of electrodeposited gold (Fig. 11). The redox current peak originated from the redox reaction of iridium oxide increases with the amount of the electrodeposited gold.

The lifetime of the films did not differ much from each

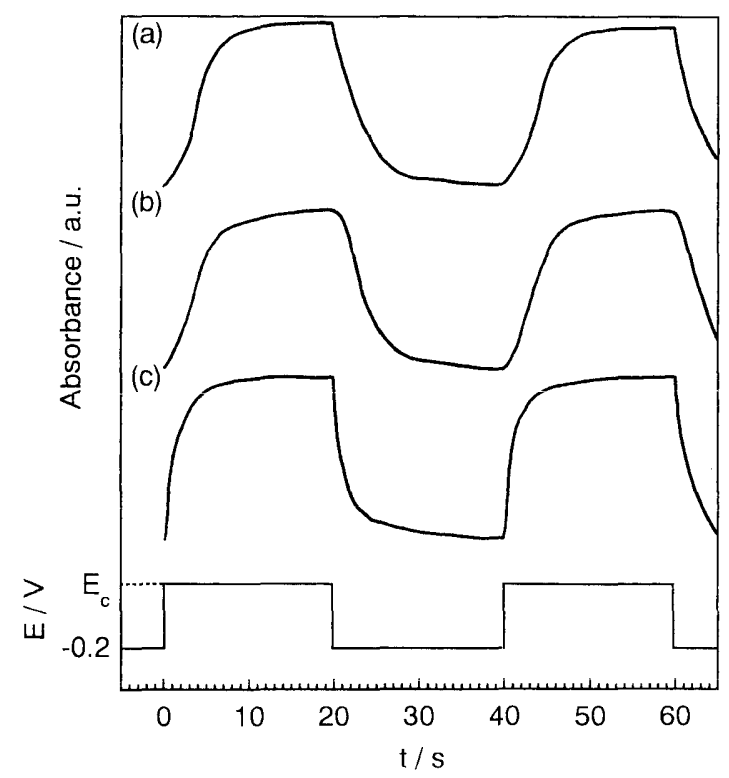

Fig. 10 Absorbance response of the iridium oxide film (a), the PPTA / iridium oxide film (b) and the PPTA / iridium oxide / $\mathrm{Au}$ film (c) in $0.1 \mathrm{~mol} \mathrm{dm}{ }^{-3} \mathrm{HClO}_{4}$ aqueous solution. The square-wave potential-time profile is shown by the lower curve of each figure: $E_{c}=+0.8(a),+1.0(b)$ and $+1.0 \mathrm{~V}(\mathrm{c})$.

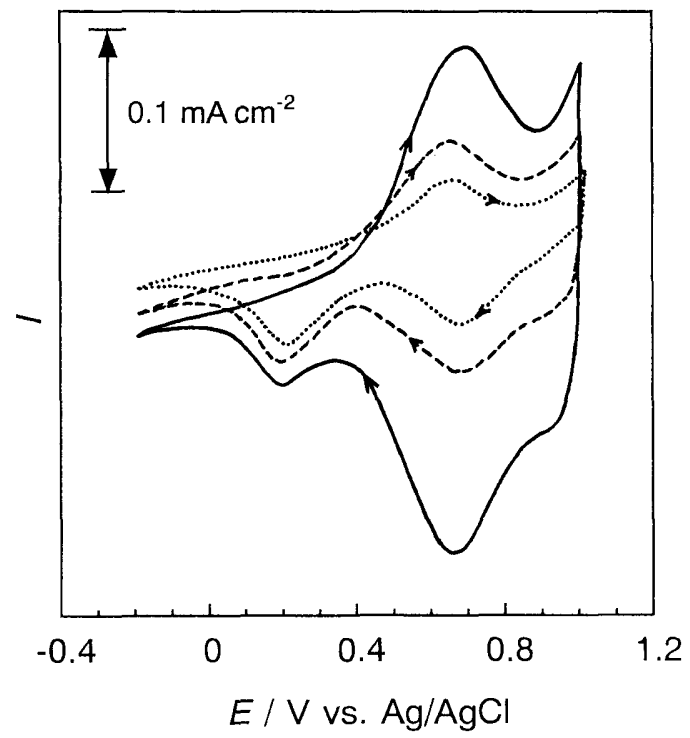

Fig. $11 \mathrm{CVs}$ at $10 \mathrm{mV} \mathrm{s}^{-1}$ of the PPTA / iridium oxide film with different Au-electrodeposited amount in $0.1 \mathrm{~mol} \mathrm{dm}^{-3}$ $\mathrm{HClO}_{4}$ aqueous solution. The charge passed during the Auelectrodeposition is $10(\cdots \cdots \cdots \cdots), 20(-\cdots \cdots)$ and $30 \mathrm{mC}$ $(\longrightarrow)$. 
other. Each color change was observable after at least 2 $\times 10^{3}$ repetitions. Unfortunately, however, no color change was seen when the number of the repetitions exceeded $10^{4}$, all the films remained permanently black blue. We are trying to improve the lifetime to the practical level.

\section{Conclusions}

Iridium oxide can be electrodeposited on a PPTA filmcoated ITO electrode, and a free-standing PPTA / iridium oxide film is easily prepared. In the oxidized state, the PYTA / iridium oxide film shows greenish blue: the maximum absorption wavelength of the PPTA / iridium oxide film was about $600 \mathrm{~nm}$. By comparing the XPSbiding energy of Ir $4 \mathrm{f}_{5 / 2}$ and $\mathrm{Ir} 4 \mathrm{f}_{7 / 2}$ electrons, the greenish blue color is due to donating of the lone pair electrons of PPTA to the indium.

The electrodeposition of gold on the PPTA / iridium oxide film can be carried out. The obtained PPTA / iridium oxide / Au film shows quite different electrochromic properties. New redox current peaks appears in the $\mathrm{CV}$ of the film and the film is colored vermilion in the reduced state and greenish blue in the oxidized state. The vermilion color is probably originated from the formation of a -Au-Cl-Ir- binuclear Cl-bridged complex and/or the plasmon absorption of the Au microparticles dispersed in the PPTA film. The vermilion-greensish blue electrochromism is expected to expand the practical ECD applicability of iridium oxide. In addition, for the color change, the switching time is less than $5 \mathrm{~s}$ and the lifetime is more than $10^{3}$ repetitions.

\section{Acknowledgments}

We thank Prof. Akira Kitani for his helpful discussions. We also thank the Nippon Sheet Glass Co. for the supply of ITO glass plates.

\section{References}

1) C. G. Granqvist, Handbook of Inorganic Electrochromic Materials, Elsevier, Amsterdam (1995).

2) S. Gottesfeld, J. D. E. McIntyre, G. Beni, and J. L. Shay, Appl. Phys. Lett., 33, 208 (1978).

3) S. Gottesfeld and J. D. E. McIntyre, J. Electrochem. Soc., 126, 742 (1979).

4) T. Yoshino, N. Baba, and K. Arai, Jpn. J. Appl. Phys., 26,
1547 (1987).

5) T. Yoshino, K. Arai, and N. Baba, Hyomen Gijutu, 41, 676 (1990).

6) K. Yamanaka, Jpn. J. Appl. Phys., 30, 1285 (1991).

7) K. Yamanaka, Jpn. J. Appl. Phys., 28, 632 (1989).

8) R. Kötz, H. Neff, and S. Stucki, J. Electrochem. Soc., 131, 72 (1984).

9) G. K. Wertheim and H. J. Guggenheim, Phys. Rev., 22, 4680 (1980).

10) Y. Y. Kleperis, A. N. Rodionov, and A. R. Lusis, Elektrokhimiya, 28, 1450 (1992).

11) R. D. Rauh and S. F. Cogan, J. Electrochem. Soc., 140, 378 (1993).

12) N. Bestaoui, E. Prouzet, P. Deniard, and R. Brec, Thin Solid Films, 235, 35 (1993).

13) M. Collomb-Dunand-Sauthier, S. Langlois, and E. Genies, J. Appl. Electrochem., 24, 72 (1994).

14) M. A. Petit and V. Plichon, J. Electroanal. Chem., 379, 165 (1994).

15) L. Servant, M. Hernandez, J. Grondin, and J. Lassegues, Ionics, 1, 351 (1995).

16) T. Yoshino, M. Satoh, T. Ohmori, H. Masuda, and N. Baba, Hyomen Gijutu, 47, 985 (1996).

17) T. Yoshino, Hyomen Gijutsu, 49, 20 (1998).

18) M. A. Petit and V. Plichon, J. Electroanal. Chem., 444, 247 (1998).

19) S. Taunier, C. Guery, and J. Tarascon, Electrochim. Acta, 44, 3219 (1999).

20) C. Barbero, R. Kötz, and O. Haas, Synth. Met., 101, 170 (1999).

21) K. Nishio, Y. Watanabe, and T. Tsuchiya, Thin Solid Films, 350, 96 (1999).

22) T. Pauporte and R. Durand, J. Appl. Electrochem., 30, 35 (2000).

23) A. Azens and C. G. Granqvist, Appl. Phys. Lett., 81, 928 (2002).

24) L. Sziraki and L. Bobics, Electrochim. Acta, 47, 2189 (2002).

25) M. Takayanagi and T. Katayose, J. Polym. Sci., Polym. Chem., 19, 1133 (1981).

26) E. K. Sichel, J. I. Gittelman, and J. Zelez, Appl. Phys. Lett., 31, 109 (1977).

27) K. Koga, S. Yamasaki, K. Narimatsu, and M. Takayanagi, Polym. J., 21, 733 (1989).

28) T. Hirayama, J. Yano, H. Ohura, and S. Yamasaki, Hyomen Gijutsu, 52, 762 (2001). 